\title{
Neurosyphilis and ocular syphilis clinical and cerebrospinal fluid characteristics: a case series
}

\author{
Características clínicas e liqúoricas de pacientes com neurossífilis e sífilis ocular: uma \\ série de casos
}

\author{
Conrado Regis Borges ${ }^{1}$, Sérgio Monteiro de Almeida ${ }^{1,3}$, Karen Sue², Jéssyca Luana Alves Koslyk1, Mario \\ Teruo Sato², Naoye Shiokawa², Hélio Afonso Ghizoni Teive?
}

\begin{abstract}
Background: During the first decade of this century, a significant increase in the incidence of syphilis was documented. Objective: To study clinical and laboratory characteristics of central nervous system and ocular syphilis. Methods: A retrospective case series of 13 patients with a clinical and laboratory diagnosis of neurosyphilis and/or ocular syphilis who had been admitted to the Neurology and Neuro-ophthalmology Service of the Hospital de Clínicas, Federal University of Paraná. Results: Nine patients had a diagnosis of neurosyphilis and two of them also had ocular syphilis. Four patients had a diagnosis of ocular syphilis alone. Among the patients with a diagnosis of neurosyphilis, six had symptomatic syphilitic meningitis, of whom one manifested as cranial nerve palsy alone, one as cranial nerve palsy plus ocular syphilis, two as transverse myelitis (syphilitic meningomyelitis), one as meningitis worsening the patient's myasthenia gravis symptoms and one as meningitis plus ocular syphilis. Additionally, we diagnosed three patients with meningovascular neurosyphilis. In the univariate analysis, patients without ocular syphilis showed greater levels of total protein and white blood cells in the cerebrospinal fluid than patients with ocular syphilis. Conclusion: This Brazilian case series of patients with neurosyphilis and ocular syphilis highlights the wide variability of this disease. A high degree of diagnostic suspicion is necessary when facing neurological and ocular symptoms for rapid diagnosis and appropriate management of patients.
\end{abstract}

Keywords: syphilis; neurosyphilis, ocular syphilis.

\section{RESUMO}

Introdução: Na primeira década deste século observou-se um aumento significativo da incidência de sífilis no mundo. Objetivo: Estudar características clínicas e laboratoriais da sífilis no Sistema Nervoso Central e da sífilis ocular. Métodos: Estudou-se, retrospectivamente, uma série de treze casos com diagnóstico clínico e laboratorial de neurossífilis e/ou sífilis ocular, admitidos aos Serviços de Neurologia ou Neuroftalmologia do Hospital de Clínicas da Universidade Federal do Paraná. Resultados: Nove pacientes tiveram diagnóstico de neurosífilis e dois destes apresentaram concomitantemente sífilis ocular. Quatro pacientes tiveram somente o diagnóstico de sífilis ocular. Dos pacientes com diagnóstico de neurosífilis, seis apresentaram meningite sifilítica sintomática, dentre os quais um se apresentou com paralisia isolada de par craniano, um com paralisia de par craniano associada sífilis ocular, dois com mielite transversa (manifestação de meningomielite), um com meningite que agravou sintomas de Miastenia Gravis e um com meningite isolada associada a sífilis ocular. Houve 3 casos de neurosífilis meningovascular. Na análise univariada, pacientes sem manifestações oculares de sífilis apresentaram maiores níveis proteína total e leucócitos do que os pacientes com sífilis ocular. Conclusão: Essa série brasileira de casos de pacientes com neurosífilis e sífilis ocular destaca a alta variabilidade clínica desta doença. Alto grau de suspeição diagnóstica é necessário quando em frente a sintomas neurológicos e oculares para rápido diagnóstico e adequado manejo dos pacientes.

Palavras-chave: Sífilis; neurossífilis, sífilis ocular.

Syphilis is a sexually transmitted disease that manifests itself as primary, secondary and tertiary forms. It affects various organ systems, including the central nervous system and ocular system. Before the antibiotic era, it was one of the greatest public health concerns worldwide. The availability of penicillin treatment, however, dramatically reduced its prevalence ${ }^{1,2,3}$ and epidemiologic importance. Nevertheless, during the first decade of this century, studies in many populations worldwide have revealed a significant increase in the incidence of syphilis and neurosyphilis, especially in some population groups, such as HIV-carriers and men who have sex with men $^{1,2,3}$. The aim of this study was to compare clinical and laboratory characteristics of ocular and central nervous system syphilis.

\footnotetext{
'Universidade Federal do Paraná, Hospital de Clínicas, Departamento de Medicina Interna, Serviço de Neurologia, Curitiba PR, Brasil;

2Universidade Federal do Paraná, Hospital de Clínicas, Serviço de Neuro-Oftalmologia, Curitiba PR, Brasil;

${ }^{3}$ Faculdades Pequeno Príncipe Curitiba, Instituto de Pesquisa Pelé Pequeno Príncipe, Curitiba PR, Brasil.

Correspondence: Conrado Regis Borges; Hospital de Clínicas, Serviço de Neurologia; Rua General Carneiro, 181/40 andar; $80060-900$ Curitiba PR, Brasil; E-mail:conradoborges@outlook.com

Conflict of interest: There is no conflict of interest to declare.

Received 16 December 2017; Received in final form 02 March 2018; Accepted 19 March 2018.
} 


\section{METHODS}

We describe a case series of patients admitted between 2013 and 2015 to the Neurology and Neuro-ophthalmology Services in the Hospital de Clínicas at the Universidade Federal do Paraná (HC-UFPR), which is a public tertiary university hospital situated in southern Brazil. We reviewed retrospectively 13 selected medical records of patients diagnosed and treated as having neurosyphilis and/or ocular syphilis. The patients were referred to the hospital by the local public health care system after an initial evaluation by a general practitioner. These cases were probably not all the neurosyphilis patients who had been diagnosed in the above-mentioned hospital, because information was retrieved from a paper-based chart system. Care was provided by the neurology and/ or ophthalmology services following the standard protocols for neurosyphilis ${ }^{1}$. This was part of a larger research study on patients with meningitis, which was approved by the ethics committee of our institution. All patients had consented to the use of the information obtained during hospitalization.

\section{Diagnosis of syphilis}

As there was clinical suspicion of syphilis, blood samples from the 13 patients were tested for syphilis using the following standard laboratory protocol adopted by the HC-UFPR Clinical Pathology Laboratory: a treponemal screening assay (chemiluminescent immunoassay), which, if reactive, was followed by the Venereal Disease Research Laboratory (VDRL) test and fluorescent treponemal antibody absorption (FTA-Abs) test. Further laboratory tests were ordered by the physicians who had examined the patients, as required. The diagnostic criteria for syphilis were reactive treponemal and/or nontreponemal tests and a clinical profile consistent with the disease.

\section{Diagnosis of ocular syphilis}

The diagnostic criteria for ocular syphilis include having a new diagnosis of syphilis (defined as having serologic evidence of syphilis) and evidence of syphilitic infection in the eye or documented ocular inflammation related to syphilis on ocular and imaging examinations $\mathrm{s}^{4,5}$.

\section{Diagnosis of neurosyphilis}

After serological diagnosis, all patients underwent lumbar puncture, and cerebrospinal fluid (CSF) cytology and the VDRL were carried out. Protein and glucose levels were also quantified. The FTA-Abs was only performed on the CSF in one patient.

Symptomatic neurosyphilis was diagnosed according to the criteria described by Marra': the clinical profile had to be consistent with neurosyphilis, with reactive CSF-VDRL and CSF white blood cell count $>5 / \mathrm{mm}^{3}$ or
CSF protein $>45 \mathrm{mg} / \mathrm{dL}^{1}$. No patient with asymptomatic neurosyphilis was included in this series.

\section{Response to treatment}

All patients were treated according to the current guidelines of neurosyphilis and ocular syphilis. Patients were considered to have responded to syphilis treatment when there was resolution, improvement or stabilization of clinical abnormalities and normalization of CSF findings ${ }^{1,2}$.

\section{Statistical analysis}

For comparative purposes, we divided the patients into two groups: patients with neurosyphilis without ocular syphilis and patients with ocular syphilis. Descriptive results were presented as median (IQR) or number (\%) as appropriate. Comparative statistics for categorical variables were performed with the chi-square test or, for continuous variables, with the Mann-Whitney test. Statistical significance was obtained with $\mathrm{p}$-values $\leq 0.05$.

\section{RESULTS}

Thirteen patients fulfilled the criteria for neurosyphilis and/or ocular syphilis between 2013 and 2015. Demographics, laboratory characteristics and CSF findings are described in Table 1. Supplementary information on the patients is shown in Table 2.

Nine patients (69.23\%) had a diagnosis of neurosyphilis. Among these, two patients also fulfilled the criteria for ocular syphilis. Four patients (30.76\%) had a diagnosis of ocular syphilis alone.

Among the nine patients diagnosed with neurosyphilis, six $(66.6 \%)$ had symptomatic syphilitic meningitis presenting with different clinical manifestations: two (22.2\%) with meningomyelitis manifesting as transverse myelitis, one $(11.1 \%)$ with cranial nerve palsy alone (peripheral facial palsy), one with cranial nerve palsy plus ocular syphilis, one (11.1\%) with meningitis that worsened the symptoms of myasthenia gravis and one with meningitis plus ocular syphilis (11.1\%). Three (33.3\%) patients had meningovascular neurosyphilis. For illustrative purposes, we describe two of the patients in Figures 1 and 2.

There was a higher proportion of male patients in the ocular syphilis group (83.3\%) than the neurosyphilis group (42.86\%), although this was not statistically significant $(\mathrm{p}=0.26)$. The neurosyphilis and ocular syphilis patients were comparable in age, gender, duration of symptoms, frequency of positivity of serum treponemal and nontreponemal tests and frequency of HIV infection between groups.

\section{CSF biochemistry and cell characteristics}

Lumbar CSF total protein concentration and the frequency of total protein increase was higher in neurosyphilis 
Table 1. Clinical and demographic characteristics of 13 patients with neurosyphilis and ocular syphilis.

\begin{tabular}{|c|c|c|c|c|}
\hline Variables & $\begin{array}{l}\text { Neurosyphilis without } \\
\text { ocular syphilis }(n=7)\end{array}$ & $\begin{array}{l}\text { Ocular syphilis } \\
\text { (total) }(n=6)\end{array}$ & $\begin{array}{l}\text { Ocular }+ \text { neurosyphilis } \\
\qquad(n=2)\end{array}$ & $\mathrm{p}$ \\
\hline \multicolumn{5}{|l|}{ Demographics } \\
\hline Age (years) - median (IQR) & $43(37.5 ; 60)$ & $49(38 ; 61.5)$ & 59 & 0.44 \\
\hline Gender (male) - n (\%) & $3(42.86 \%)$ & $5(83.3 \%)$ & $1(50 \%)$ & 0.26 \\
\hline \multicolumn{5}{|l|}{ Symptoms } \\
\hline Symptom duration (days) - median (IQR) & $187.5(10.5 ; 540)$ & $270(180 ; 360)$ & ---- & - \\
\hline \multicolumn{5}{|l|}{ Serum } \\
\hline$H I V+-n(\%)$ & $2(28.6 \%)$ & $1(16.7 \%)$ & 0 & \\
\hline CD4+ - median (IQR) & $111.5(97.2 ; 125.7)$ & ---- & --- & \\
\hline CD4+ Nadir- median (IQR) & $88(62 ; 114)$ & ---- & --- & \\
\hline Viral load - median (IQR) & $1.8 \times 10^{5}\left(1.5 \times 10^{5} ; 2.2 \times 10^{5}\right)$ & ---- & ---- & \\
\hline Reactive $\mathrm{Cl}-\mathrm{n}(\%)$ & $6(100 \%)$ & $6(100 \%)$ & $2(100 \%)$ & \\
\hline Reactive VDRL - n (\%) & $3(42.8 \%)$ & $6(100 \%)$ & $2(100 \%)$ & 0.55 \\
\hline Reactive FTA-Abs - n (\%) & $4(80 \%)$ & $4(80 \%)$ & $1(50 \%)$ & \\
\hline \multicolumn{5}{|l|}{ CSF } \\
\hline Reactive VDRL - n (\%) & $2(28.6 \%)$ & $1(20 \%)$ & $1(50 \%)$ & \\
\hline Reactive FTA-Abs - n (\%) & ----- & $1(100 \%)$ & $1(50 \%)$ & \\
\hline WBC cell/mm³ - median (IQR) & $47(4 ; 72)$ & $2.5(1 ; 23.5)$ & & 0.07 \\
\hline WBC $>5$ cells $/ \mathrm{mm}^{3}-\mathrm{n}(\%)$ & $5(71.4 \%)$ & $1(16.67 \%)$ & $1(50 \%)$ & \\
\hline Protein mg/dL- median (IQR) & $114(70.70 ; 407.7)$ & $33,75(28,05 ; 59.1)$ & & 0.03 \\
\hline Protein $>45 \mathrm{mg} / \mathrm{dL}-\mathrm{n}(\%)$ & $6(85.7 \%)$ & $1(16.67 \%)$ & 0 & 0.02 \\
\hline Glucose mg/dL- median (IQR) & $52(44.50 ; 114.0)$ & $58(49.5 ; 6.5)$ & & 0.18 \\
\hline Lactic Acid mmol/L- median (IQR) & $2.05(1.25 ; 3.2)$ & - & & \\
\hline
\end{tabular}

than in ocular syphilis ( $\mathrm{p}=0.03,0.02$ respectively); white blood cell count and the frequency of patients with pleocytosis was higher in those with neurosyphilis than in those with ocular syphilis although it did not reach statistical significance ( $p=0.073 ; 0.10$ ) between groups (both were greater in the neurosyphilis group).

\section{Treatment and evolution}

All patients were treated with aqueous crystalline penicillin $\mathrm{G}$ for 14 days (nine patients) or for 10 days (one patient), or with ceftriaxone for 14 days (three patients). The reason that the treatment of one patient was reduced to 10 days was because of the almost asymptomatic clinical profile she presented with and the good response to the treatment of the myasthenic crisis. In the follow-up, three patients $(23.1 \%)$ showed complete improvement, seven $(53.8 \%)$ showed partial improvement, one $(7.6 \%)$ showed no improvement $(7.6 \%)$ and two were lost to follow-up (15.3\%).

\section{DISCUSSION}

\section{Neurosyphilis \\ Demographics and coinfection with HIV}

In the first decade of the 2000s, the incidence of syphilis increased significantly, especially in certain population groups $^{1,3}$. The main risk factor associated with this change was HIV coinfection ${ }^{1,2,3}$, which affects the severity of syphilis and increases the likelihood of central nervous system involvement ${ }^{6,7}$. In our case series, the prevalence of comorbidities due to HIV was similar to that commonly reported in the literature. Two of the nine patients with neurosyphilis $(22.2 \%)$ had HIV-positive serology, a prevalence similar to that of the population in the United States of America $(22-25 \%)^{8}$. Two of the HIV-positive patients manifested transverse myelitis, which may be associated with the HIV infection ${ }^{9}$, although this is unlikely because of the dramatic clinical improvement post-penicillin $\mathrm{G}$ observed in these patients. 


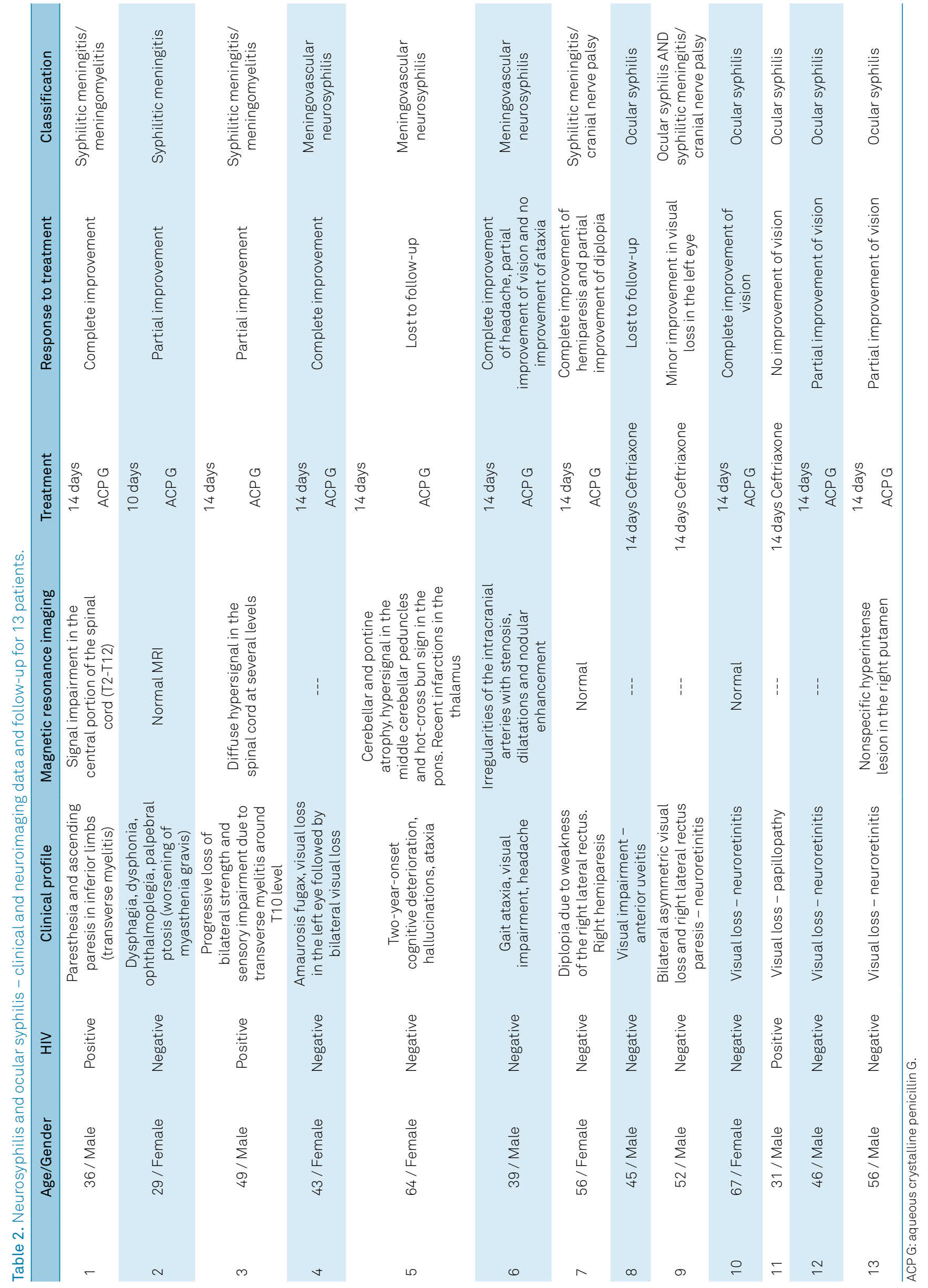



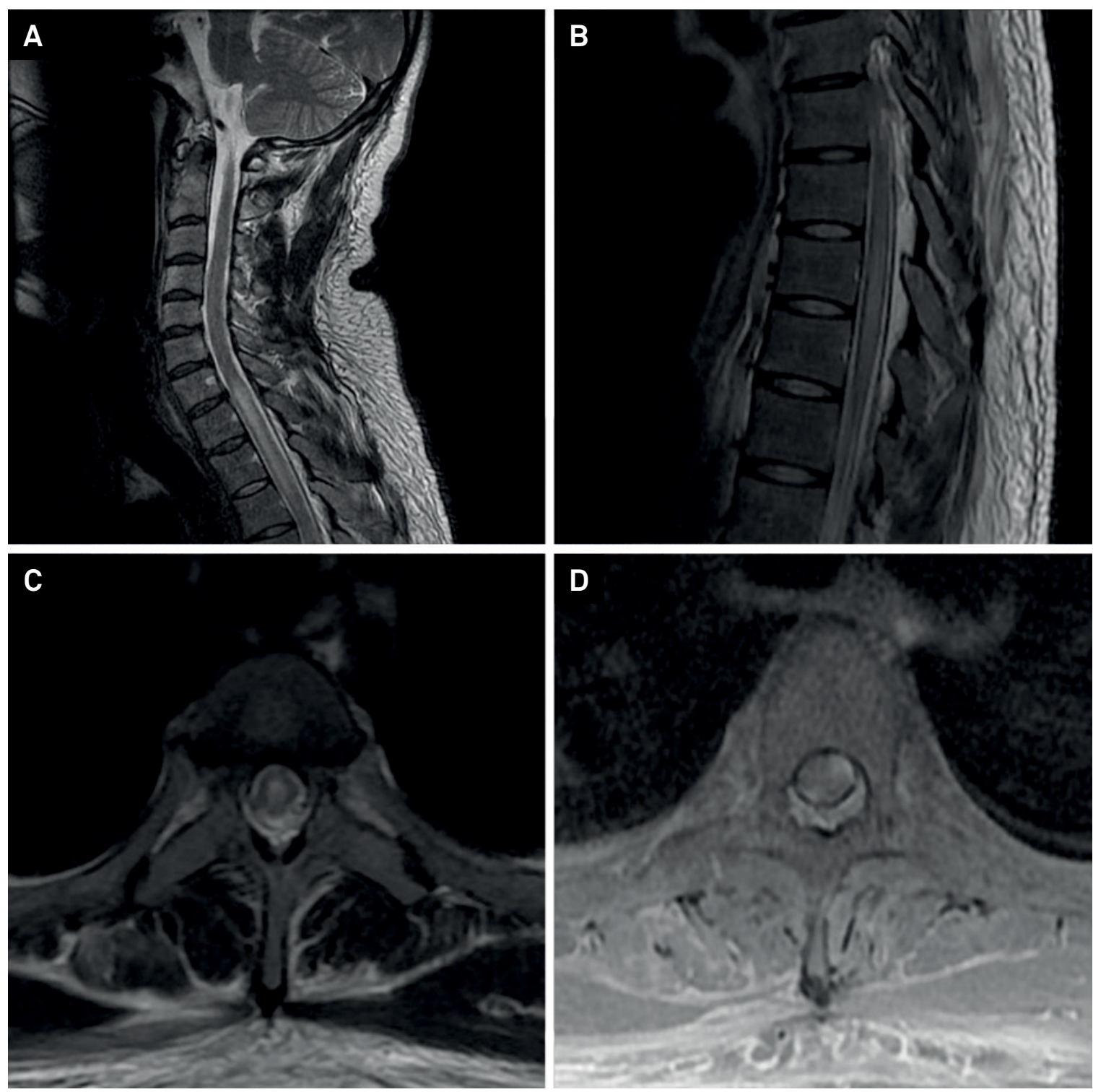

Figure 1. MRI of the vertebral column of a patient with transverse myelitis caused by neurosyphilis. A and B: Sagittal T2-weighted images of cervicothoracic vertebral column showing a hyperintense lesion affecting spinal cord segments from C6-C7 to T11-T12; C: Axial T2-weighted MRI showing hyperintensity involving most of the circumference of the spinal cord; D: Axial T1-weighted postgadolinium MRI showing contrast enhancement in two different areas of the spinal cord.

A study, presented at the annual Conference on Retroviruses and Opportunistic Infections in $2017^{10}$, observed that some clinical symptoms, such as photophobia, vision loss, gait incoordination and moderate or severe hearing loss, presenting in positive HIV patients, could predict the diagnosis of neurosyphilis. One of the HIV-positive patients showed vision loss, although this patient did not meet the CSF criteria for neurosyphilis.

Another important risk factor for syphilis (and neurosyphilis) is male sex and the group of men who have sex with $m^{1,2,3}$. However, in our case series we observed a greater frequency of female patients with neurosyphilis (57\%). One possible explanation is that most of the patients with HIV and AIDS who are admitted to our hospital are managed solely by the infectious diseases team, and these patients were not included in this series.

\section{Clinical manifestations}

In this case series, we observed the characteristic broad clinical spectrum of neurosyphilis. The clinical manifestations of neurosyphilis are classified according to whether they are associated with the early or late forms of the disease.

Early forms usually occur a few months to a few years after the primary infection and can manifest as asymptomatic or symptomatic syphilitic meningitis and meningovascular neurosyphilis.

Late forms usually occur years to decades after the primary infection and can affect the brain, causing dementia paralytica (general paresis of the insane), and the spinal cord, resulting in tabes dorsalis ${ }^{1,2,3,11,12}$. No cases of paralytic dementia or tabes dorsalis were observed in our study, in agreement with reports in the literature that manifestations 
A

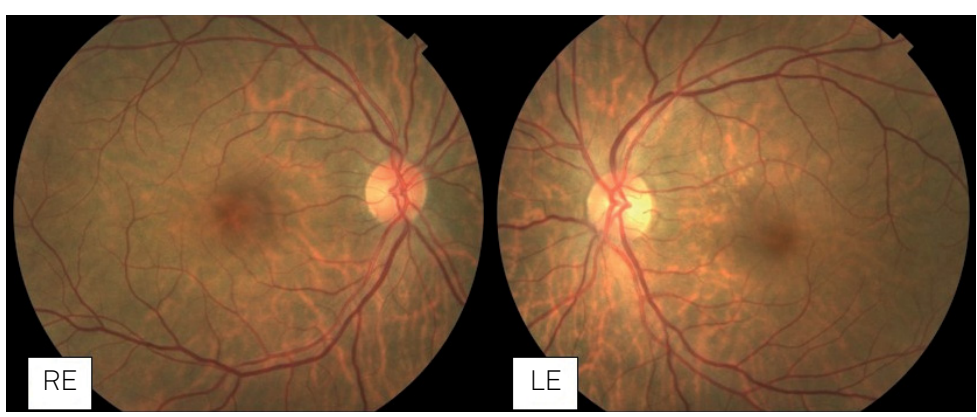

C

RE
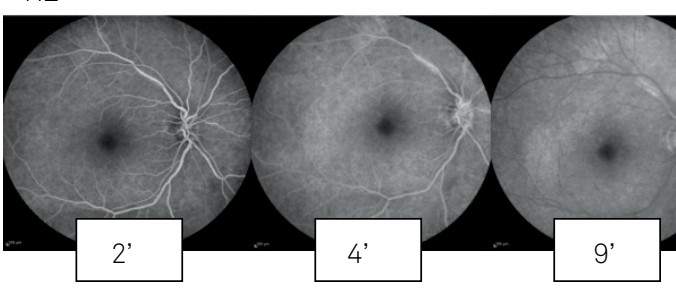

9'

LE

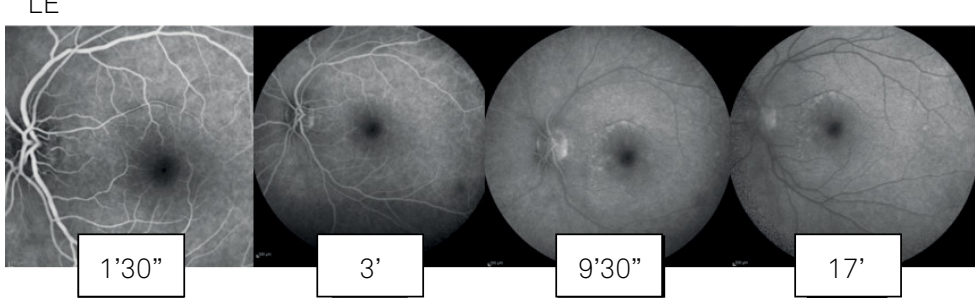

LE
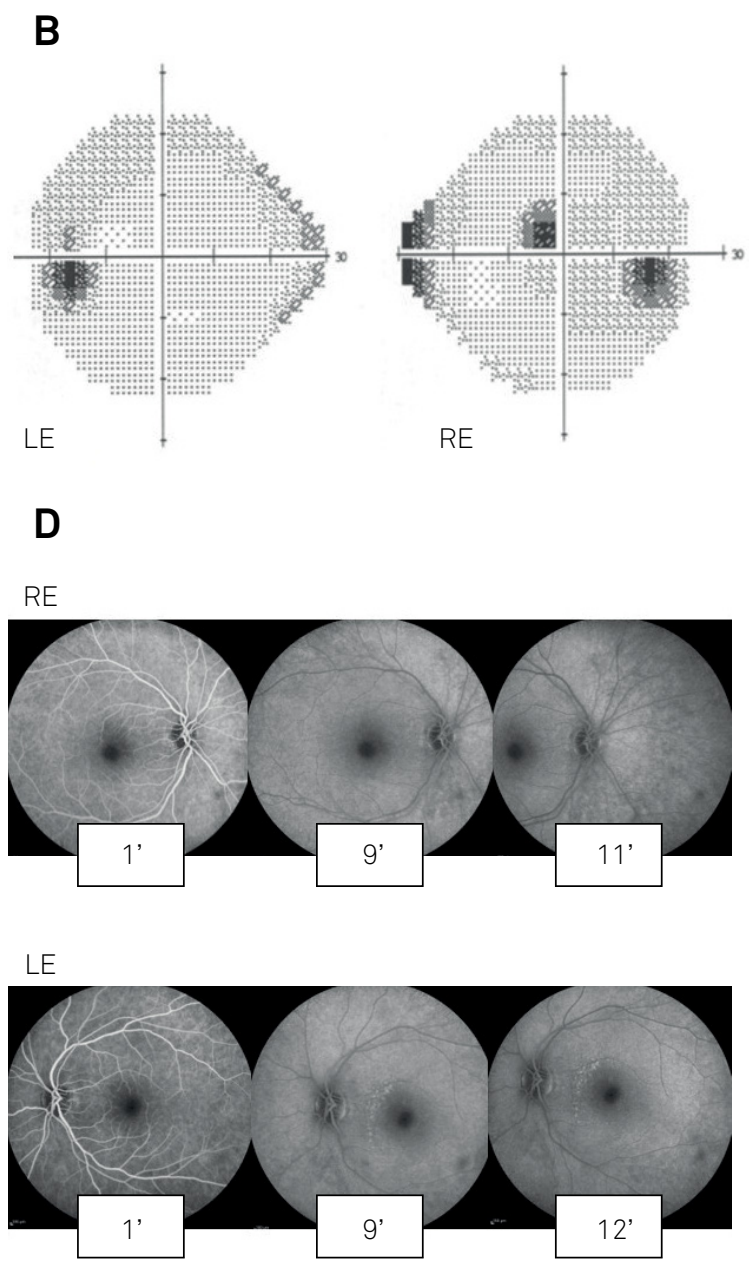

D

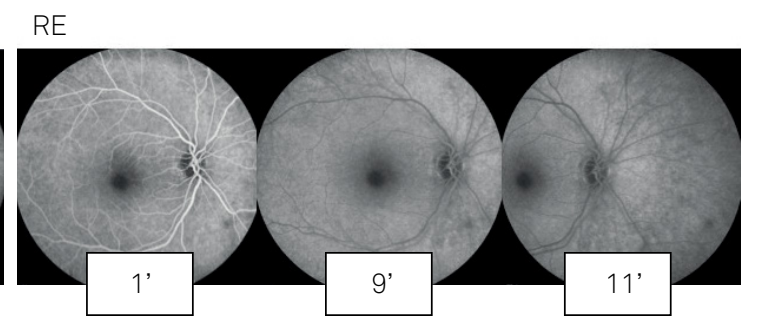

Figure 2. Workup of a 67-year-old female with neuroretinitis caused by neurosyphilis. A: normal fundoscopy. B: visual field examination showing central scotoma and impairment of the nasal peripheral visual field in the right eye (RE) and mild impairment of the nasal peripheral visual field in the left eye (LE). C: Fluorescein angiography revealing hyperfluorescence in the right superior temporal arch and papilla after four minutes and in the left papilla and macula after nine minutes, suggesting neuroretinitis. D: Fluorescein angiography after treatment showing an improvement in the macular and papillary edemas, as well as a reduction in leakage in the optic disc and retina in both eyes.

of late neurosyphilis have been observed less frequently since the advent of antibiotics ${ }^{1,2}$. Instead, most of the neurosyphilis patients studied here showed symptoms associated with syphilitic meningitis. Two patients presented with cranial nerve palsy, a common manifestation of the early form of syphilitic meningitis that is frequently the first clinical symptom of the disease ${ }^{1,2,3,6}$. Two others had a clinical profile and MRI consistent with meningomyelitis but responded very well to treatment with penicillin, supporting the diagnosis; HIV serology was positive in both these patients.

While tabes dorsalis used to be the most common spinal cord manifestation of neurosyphilis in the preantibiotic era, it has now been superseded by meningomyelitis, which develops, on average, six years after infection, although this can vary between 1-30 years ${ }^{1,2,3,13}$. Meningomyelitis is in fact a very rare form ${ }^{6}$ caused by spinal cord infections secondary to syphilitic meningitis ${ }^{1}$. Its onset is insidious and is characterized by weakness and/ or paresthesia starting in the lower limbs, which may be 
neurosyphilis. Meningovascular neurosyphilis may occur 5-10 years after the initial infection and may manifest as arteritis, resulting in reduced arterial caliber and culminating in thrombosis followed by ischemic strokes, which may occur repeatedly. Unlike traditional stroke syndromes, it can present without vascular risk factors and at a young age ${ }^{1,2,3}$. The CSF-VDRL is considered the gold standard for diagnosis of neurosyphilis but has low sensitivity ( from $30 \%$ to $70 \%)^{1,2}$. In our series, there were nine neurosyphilis patients, of whom only three had reactive CSFVDRL (33\%). The lack of assessment of the IgG index in our laboratory may have contributed to this low sensitivity.

\section{OCULAR SYPHILIS}

\section{Demographics, coinfection with HIV and disease manifestations}

An American study of demographic characteristics of ocular syphilis showed similar mean ages $(49.4 \pm 16.5)$ and sex (male $74 \%$ ) to the results presented here ${ }^{16,17}$.

Because ocular syphilis is frequently found in association with HIV, serological HIV tests should be performed in all patients with a diagnosis of ocular syphilis. While some studies report high HIV-positive rates in patients with ocular syphilis (up to $70 \%)^{18}$, we observed a rate of only $16.6 \%(1 / 6)$. This may be explained by a selection bias, considering that the patients with ocular syphilis came from an ophthalmology service that provides care to the general population. Another possible explanation is the difference in the demographic pattern of the distribution of syphilis in developing countries in comparison with developed countries. While the latter show a higher prevalence of patients with syphilis and positive HIV in men who have sex with men, the former exhibit a higher prevalence of older people without these conditions.

Corroborating the data in the literature, this study found five patients with disorders of the posterior pole (four with neuroretinitis and one with optic neuritis) and one with anterior uveitis. Currently, the frequency of syphilis patients diagnosed by ophthalmologists is unknown, but the potential for successful treatment is very high ${ }^{19}$.

\section{COMPARISON OF CSF DATA OF PATIENTS WITH NEUROSYPHILIS AND OCULAR SYPHILIS}

This study compared the CSF samples of patients with a diagnosis of neurosyphilis with those with a diagnosis of ocular syphilis. Only $33 \%$ of the patients with ocular syphilis also showed CSF impairments that led to the diagnosis of neurosyphilis, and this differs from the literature about ocular syphilis, which shows $60 \%$ of lymphocytic pleocytosis, elevated protein or both in the $\mathrm{CSF}^{20}$. The patients with neurosyphilis exhibited higher protein levels and a trend to having more white blood cells in the CSF in comparison with the patients with ocular syphilis. Furthermore, only one sample showed a positive CSF FTA-Abs and no one exhibited a positive CSF-VDRL result. Despite the fact that ocular syphilis is not always accompanied by syphilitic meningitis ${ }^{21}$, this frequency seems low. However, the small sample in this case series does not allow the generalization of this data and points to the need for further studies.

All the patients with ocular syphilis had reactive serum VDRL and FTA-Abs, pointing to a diagnosis of syphilis. In four patients, the ophthalmological evaluation was consistent with neuroretinitis, which is strongly suggestive of neurosyphilis ${ }^{22}$. The unavailability of the FTA-Abs test in the CSF may have lessened the sensitivity toward the diagnosis of neurosyphilis. Although nontreponemal tests are used to screen for syphilis, they have the disadvantage of having low sensitivity and specificity, especially in CSF samples, unlike the FTA-Abs test, which is highly sensitive and, when negative, can exclude a diagnosis of neurosyphilis ${ }^{19,22}$. In a 21-patient case series, for example, $75 \%$ of patients with ocular syphilis had a nonreactive VDRL but $100 \%$ had a positive serum FTA-Abs ${ }^{23}$.

However, it is necessary to point out that no laboratory study has proven sufficiently sensitive or specific to serve as a single test for the definitive diagnosis of neurosyphilis. The diagnosis of syphilis has remained more difficult than the diagnosis of most other infections. The standard diagnosis of neurosyphilis is based on an increased CSF white blood cell count and/or a reactive CSF-VDRL test result. The CSF abnormalities include elevated protein levels and pleocytosis, which are found in up to $70 \%$ of patients. The FTA-Abs, despite being a good auxiliary test, has shown a high rate of false positives and is not recommended by most of the guidelines for the diagnosis of neurosyphilis ${ }^{1,21}$.

Although the Centre for Disease Control recommendation from 2015 suggests a lumbar puncture in all patients with ocular syphilis, the literature lacks data describing the frequency of neurosyphilis among the patients diagnosed with ocular syphilis. One explanation for this could be that a lumbar puncture is only indicated in selected cases, such as syphilis with neurological involvement, patients with a relapse, before treatment with nonpenicillin regimens and infants with congenital syphilis ${ }^{24}$.

In conclusion, the case series presented here allowed some important features currently attributed to neurosyphilis and ocular syphilis to be reviewed. It brings attention to some clinical presentations of neurosyphilis that are different from its classic manifestations. It also discusses some patients with ocular syphilis, which is a manifestation that is commonly neglected by the neurologist. The study's limitations are the few patients studied and its retrospective case series design, which limits the collection of clinical data and precludes the description of all patients among the population. Moreover, we did not perform the IgG index of the CSF samples, which could help to identify intrathecal synthesis of IgG and increase the diagnostic sensitivity for syphilis in the CSF. 
Syphilis continues to be an important disease in neurology and in neuro-ophthalmology, especially in certain epidemiological risk groups, such as men who have sex with men and persons living with HIV. In view of the reemergence of this disease in the first decade of this century, neurologists and ophthalmologists should consider a possible diagnosis of syphilis in many different clinical contexts. Moreover, it is important to observe the clinical and epidemiological particularities of the disease in the post-antibiotic era. It should be remembered that it was not without reason that Osler called this disease the "Great Imitator".

\section{References}

1. Marra CM. Neurosyphilis. Continuum (Minneap Minn). 2015 Dec;21 6 Neuroinfectious Disease:1714-28.

2. Berger JR, Dean D. Neurosyphilis. Handb Clin Neurol. 2014;121:1461-72. https://doi.org/10.1016/B978-0-7020-4088-7.00098-5

3. Bhai S, Lyons JL. Neurosyphilis update: atypical is the new typical. Curr Infect Dis Rep. 2015 May;17(5):481. https://doi.org/10.1007/s11908-015-0481-x

4. Woolston SL, Dhanireddy S, Marrazzo J. Ocular syphilis: a clinical review. Curr Infect Dis Rep. 2016 Nov;18(11):36. https://doi.org/10.1007/s11908-016-0542-9

5. Davis JL. Ocular syphilis. Curr Opin Ophthalmol. 2014 Nov;25(6):513-8. https://doi.org/10.1097/ICU.0000000000000099

6. Marra CM. Update on neurosyphilis. Curr Infect Dis Rep. 2009 Mar;11(2):127-34. https://doi.org/10.1007/s11908-009-0019-1

7. Gaudio PA. Update on ocular syphilis. Curr Opin Ophthalmol. 2006 Dec;17(6):562-6. https://doi.org/10.1097/ICU.0b013e328010a9b5

8. Chahine LM, Khoriaty RN, Tomford WJ, Hussain MS. The changing face of neurosyphilis. Int J Stroke. 2011 Apr;6(2):136-43. https://doi.org/10.1111/j.1747-4949.2010.00568.x

9. Andrade P, Figueiredo C, Carvalho C, Santos L, Sarmento A. Transverse myelitis and acute HIV infection: a case report. BMC Infect Dis. 2014 Mar;14(1):149. https://doi.org/10.1186/1471-2334-14-149

10. Davis AP, Stern J, Dunaway S, Tantalo L, Sahi S, Crooks A et al. How well do neurologic symptoms identify hiv-infected individuals with neurosyphilis? In: Annals of Conference on Retroviruses ans Oppotunistic Infections; 2017 Feb 13-16; Seattle, USA. Abstract number: 749.

11. Ghanem KG. Neurosyphilis: a historical perspective and review. CNS Neurosci Ther. 2010 Oct;16(5):e157-68. https://doi.org/10.1111/j.1755-5949.2010.00183.x

12. Nitrini R. The history of tabes dorsalis and the impact of observational studies in neurology. Arch Neurol. 2000 Apr;57(4):605-6. https://doi.org/10.1001/archneur.57.4.605

13. Berger JR. Neurosyphilis and the spinal cord: then and now.J Nerv Ment Dis. 2011 Dec;199(12):912-3. https://doi.org/10.1097/NMD.0b013e31823928e8
14. Chilver-Stainer L, Fischer U, Hauf M, Fux CA, Sturzenegger M. Syphilitic myelitis: rare, nonspecific, but treatable. Neurology. 2009 Feb;72(7):673-5. https://doi.org/10.1212/01.wnl.0000342460.07764.5c

15. Wüllenweber M, Schneider U,Hagenah R [Myasthenia gravis in AIDS and neurosyphilis]. Nervenarzt. 1993 Apr;64(4):273-7. German.

16. Moradi A, Salek S, Daniel E, Gangaputra S, Ostheimer TA, Burkholder BM et al. Clinical features and incidence rates of ocular complications in patients with ocular syphilis. Am J Ophthalmol. 2015. Feb;159(2):334-43. https://doi.org/10.1016/j.ajo.2014.10.030

17. Balba GP, Kumar PN, James AN, Malani A, Palestine AG, Welch JN et al. Ocular syphilis in HIV-positive patients receiving highly active antiretroviral therapy. Am J Med. 2006 May;119(5):448.e21-5. https://doi.org/10.1016/j.amjmed.2005.11.016

18. Malerbi FK, Ghanem RC, Chiang J, Takahashi WY. Descolamento de retina exsudativo bilateral associado a alterações de comportamento em paciente com diagnóstico de neurossífilis: relato de caso. Arq Bras Oftalmol. 2006 Jan-Feb;69(1):115-8. https://doi.org/10.1590/S0004-27492006000100022

19. Chao JR, Khurana RN, Fawzi AA, Reddy HS, Rao NA. Syphilis: reemergence of an old adversary. Ophthalmology. 2006 Nov;113(11):2074-9. https://doi.org/10.1016/j.ophtha.2006.05.048

20. Spoor TC, Ramocki JM, Nesi FA, Sorscher M. Prevalence of FTA-ABS reacrivity and cerebrospinal fluid findings. J Clin Neuroophthalmol. 1987;7(4):191-5.

21. Fishman RA. Cerebrospinal fluid in diseases of the nervous system. Philadelphia: Saunders; 1992.

22. Hernández-Bel P, Gómez-Maestra MJ, Torrijos-Aguilar A, López J, Vilata JJ, Alegre V. Ocular syphilis: a rare presentation of secondary syphilis in an immunocompetent patient. Actas Dermosifiliogr. 2010. Mar;101(2):184-6. https://doi.org/10.1016/S1578-2190(10)70611-9

23. Rodrigues RA, Nascimento HM, Muccioli C. Yellowish dots in the retina: a finding of ocular syphilis? Arq Bras Oftalmol. 2014 Oct;77(5):324-6. https://doi.org/10.5935/0004-2749.20140081

24. Majunder PD, Chen EJ, Shah J, Ho DC, Biswas J, Yin LS et al. Ocular syphilis: an update. Ocul Immunol Inflamm. 2017 Oct;11:1-9. https://doi.org/10.1080/09273948.2017.1371765 